\title{
A IMPORTÂNCIA DO TESTE DA LINGUINHA E DA INTERVENÇÃO DE UMA EQUIPE MULTIPROFISSIONAL EM CRIANÇAS COM ANQUILOGLOSSIA POR MEIO DO PROTOCOLO DE MARTINELLI
}

\section{LA IMPORTANCIA DE LA PRUEBA DE LENGUA Y DE LA INTERVENCIÓN DEL EQUIPE MULTIPROFISSIONAL EM NIÑOS COM ANQUILOGLOSIA A TRAVÉS DEL PROTOCOLO DE MARTINELLI}

\section{THE IMPORTANCE OF THE LITTLE TONGUE TEST AND THE INTERVENTION OF A MULTIPROFESSIONAL TEAM ON CHILDREN WITH ANKYLOGLOSSIA THROUGH THE MARTINELLI PROTOCOL}

\begin{abstract}
Danielle Pereira de Lima ${ }^{1}$; Alana Tainá Rodrigues Barbosa ${ }^{2}$; Eduardo Ramos da Silva ${ }^{3}$; Vytor Paulo Conserva Silva ${ }^{4}$; Artemísia Ruth Arruda Lucena Veras ${ }^{5}$
\end{abstract}

DOI: $\underline{\text { https://doi.org/10.31692/978-65-991061-9-4.104-106 }}$

\section{INTRODUÇÃO}

O teste da linguinha é um protocolo específico de avaliação do frênulo da língua em bebês para diagnóstico precoce da anquiloglossia, que podem comprometer algumas funções exercidas pela língua. É realizado uma avaliação anatomofuncional por meio do protocolo de Martinelli. O projeto de lei 4.832/12 aprovado em 20 de Junho do ano de 2014 (Brasil, 2014), obriga a realização do protocolo de avaliação do frênulo da língua em bebês, em todos os hospitais e maternidades do Brasil. Externamos a importância do teste, que por sua vez, permite ao bebê ser diagnosticado e na possibilidade de uma alteração, ser indicado ao tratamento precoce dos movimentos limitados da língua, ocasionados pela anquiloglossia, que pode comprometer as funções: sucção, deglutição, mastigação e fala.

\section{RELATO DE EXPERIÊNCIA}

Os projetos Língua Solta e Teste da Linguinha, são compostos por uma equipe multiprofissional, como Fonoaudiólogos, Psicólogos, Cirurgiões Dentistas, Nutricionista e graduandos nas áreas de Fonoaudiologia e Odontologia realizado na Universidade Federal de Pernambuco - UFPE. Em média são realizados 10 atendimentos por expediente, além desses atendimentos agendados, existe a demanda espontânea, a maioria dos casos são encaminhados ao projeto por médicos Pediatras. A avaliação é composta por história clínica, avaliação anatomofuncional, avaliação da sucção não nutritiva e nutritiva, a partir disso, o Fonoaudiólogo

\footnotetext{
${ }^{1}$ Fonoaudiologia, Centro Universitário São Miguel, fgadanielle@gmail.com

${ }^{2}$ Fonoaudiologia, Centro Universitário São Miguel, alana.taina@gmail.com

${ }^{3}$ Fonoaudiologia, Centro Universitário São Miguel, eduardo.ramos.fono@gmail.com

${ }^{4}$ Fonoaudiologia, Centro Universitário São Miguel, vytorpaulo78@gmail.com

${ }^{5}$ Mestre em Ciências da Linguagem, Centro Universitário São Miguel, artemisiaveras@ yahoo.com.br
} 
realiza o diagnóstico. Caso seja comprovada anquiloglossia e haja a necessidade de uma intervenção cirúrgica, onde é função exclusiva do cirurgião dentista, a cirurgia será redefinida após uma semana, ou por vezes mais de uma semana, já que atendemos um número considerável de pessoas carentes e algumas delas não possui as condições necessárias para ter um rápido resultado dos exames em mão, são eles: Hemograma, Coagulograma e Glicemia. Os bebês que ainda mamam, após a intervenção cirúrgica, são colocados no peito, pois se observa que além de acalmá-los o leite materno tem ação cicatrizante e diminui o fluxo na região. Os psicólogos são extremamente importantes dando suporte emocional a família, que em maioria desconhecem a técnica utilizada e que os profissionais são capacitados e habilitados na realização da frenotomia, também conhecida como "pique na língua". Entre Janeiro e Setembro foram atendidos 606 crianças, porém desses, entre a faixa etária de 0 a 2 foram atendidos 567 , sendo 350 do sexo masculino e 217 do sexo feminino. Crianças de 0 a 2 anos possuem uma vasta quantidade de células, águas e fibras colágenas no tecido epitelial contribuindo para esta cicatrização espontânea. Observamos que algumas mães conseguem notar a diferença positiva da pega ao peito, tornando a amamentação mais eficaz. É perceptível também uma melhoria na sucção e deglutição do bebê. Geralmente, a maioria das crianças encaminhadas ao projeto são lactentes, crianças acima de dois anos são minoria. Por vezes, o problema não é apenas a presença da anquiloglossia, mas também a falta de estímulo dos pais ou responsáveis, muitos casos a família têm dificuldade de acesso a orientação fonoaudiológica. Os que não são mais dependentes do leite materno recebem uma orientação nutricional.

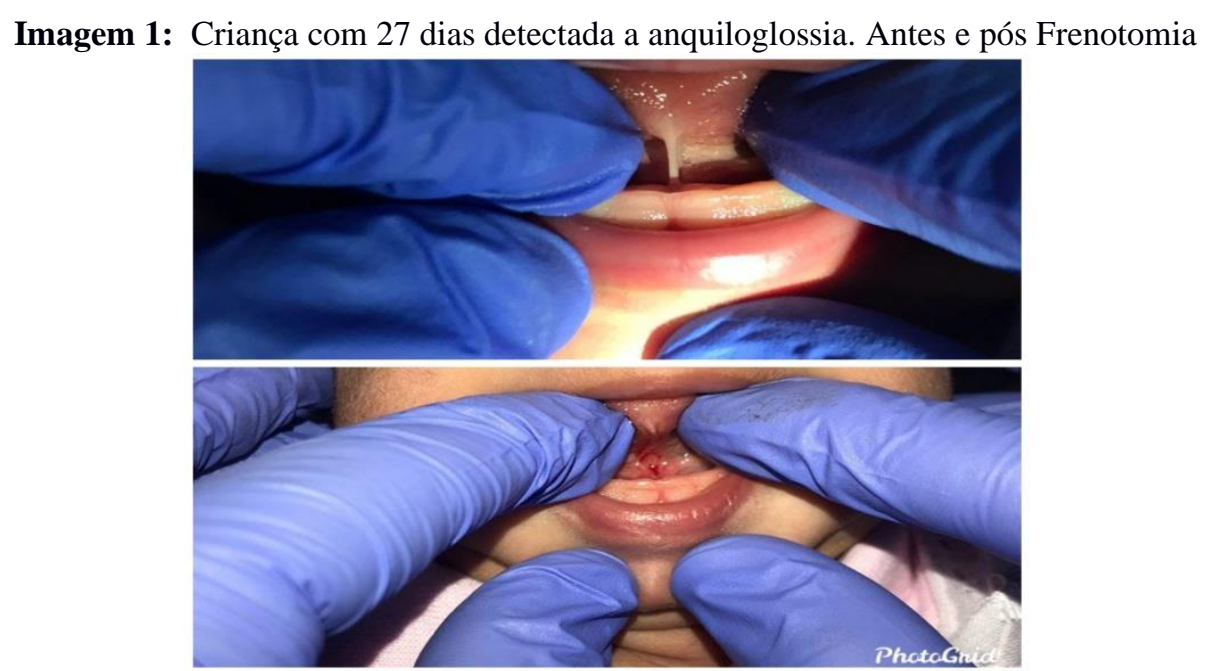

Fonte: Própria (2019)

\section{CONSIDERAÇÕES}

Podemos considerar que os projetos Língua Solta e Teste da Linguinha, é uma via de mão dupla, pois está nos permitindo crescer como estudantes de Fonoaudiologia, além de 
contribuir com a saúde pública promovendo qualidade de vida a população. Externamos nesse relato de experiência a importância da realização do teste da linguinha, não apenas pela sua obrigatoriedade definida pela legislação, mas em virtude da qualidade de vida de crianças e lactentes atendidos.

\section{REFERÊNCIAS}

BRASIL. PL 4832/2012, DE 20 DE JUNHO DO ANO DE 2014. Protocolo de avaliação do frênulo da língua em bebês recém-nascidos - "teste da linguinha", Brasíla, DF, jun 2014. Disponível em: <https://www.camara.leg.br/proposicoesWeb/fichadetramitacao?idProposicao=562681 >. Acesso em: 17 out. 2019.

MARTINELLI RLC, MARCHESAN IQ, BERRETIN-FELIX G Avaliação do frênulo lingual. Rev. CEFAC. 2013 Mai-Jun; 15(3):599-610.

MARTINELLI, ROBERTA LOPES DE CASTRO Validação do Protocolo de avaliação do frênulo da língua em bebês/ Roberta Lopes de Castro Martinelli. - Bauru, 2015. 104 p. :Il.; $30 \mathrm{~cm}$. 